\title{
Performance and fate of organics in a pilot MBR-NF for treating antibiotic production wastewater with recycling NF concentrate
}

\author{
Jianxing Wang ${ }^{a}$, Kun $\mathrm{Li}^{\mathrm{a}}$, Yuansong Wei ${ }^{\mathrm{a}, *}$, Yutao Cheng ${ }^{\mathrm{a}, \mathrm{b}}$, Dongbin Wei ${ }^{\mathrm{a}}$, Mingyue $\mathrm{Li}^{\mathrm{c}}$ \\ ${ }^{a}$ Research Center for Eco-Environmental Sciences, Chinese Academy of Sciences, P.O. Box 2871, Beijing 100085, China \\ ${ }^{\mathrm{b}}$ CCID Consulting Co., Ltd, Beijing 100048, China \\ ${ }^{\mathrm{c}}$ Wuxi Fortune Pharmaceutical Co. Ltd, Wuxi 214046, China
}

\section{H I G H L I G H T S}

- MBR-NF with NF concentrate recycling was tested for antibiotic-wastewater treatment.

- The system was effective for antibiotic production wastewater treatment and reuse.

- The MBR-NF process resulted in excellent water quality and a high water yield of $92 \%$.

- Organic pollutants in the wastewater were almost completely retained by the NF.

\section{A R T I C L E I N F O}

\section{Article history:}

Received 4 August 2014

Received in revised form 7 November 2014

Accepted 15 November 2014

Available online 2 December 2014

Handling Editor: Shane Snyder

\section{Keywords:}

Antibiotic production wastewater

Membrane bioreactor

Nanofiltration

Water yield

Organics fate

Microbial community

\begin{abstract}
A B S T R A C T
A double membrane system comprising a membrane bioreactor (MBR) combined with a nanofiltration (NF) membrane was investigated on a pilot scale for the treatment of antibiotic production wastewater over a three-month period at a pharmaceutical company in Wuxi, China. By recycling the NF concentrate, the combined MBR-NF process was shown to be effective for the treatment of antibiotic production wastewater, resulting in excellent water quality and a high water yield of $92 \pm 5.6 \%$. The water quality of the pilot-scale MBR-NF process was excellent; e.g., the concentrations of $\mathrm{TOC}, \mathrm{NH}_{4}^{+}-\mathrm{N}$, TP were stable at $5.52,0.68,0.34 \mathrm{mg} \mathrm{L}^{-1}$, respectively, and the values of turbidity and conductivity of the NF permeate were $0.15 \mathrm{NTU}$ and $2.5 \mathrm{mS} \mathrm{cm}^{-1}$, respectively; these values meet China's water quality standard requirements for industrial use (GB21903-2008). Not only were the antibiotic removal rates of spiramycin (SPM) and new spiramycin (NSPM) over 95\%, the acute toxicity was also drastically reduced by the MBR-NF pilot system. The main organics in the MBR effluent were proteins, polysaccharides, and humic-like substances; they were almost completely retained by the NF membrane and further biodegraded in the MBR because the NF concentrate was recycled. The microbial community of the MBR did not significantly change with the recycling of the NF concentrate.
\end{abstract}

() 2014 Elsevier Ltd. All rights reserved.

\section{Introduction}

The amount of pharmaceutical wastewater discharged globally is large, and it is difficult to treat such wastewater because of the high concentration and recalcitrant of pollutants (Chelliapan et al., 2006). The gross industrial production of the pharmaceutical industry in China accounts for $1.7 \%$ of all domestic industrial output, whereas the amount of wastewater discharged contributed to as much as $2 \%$ (Pharmaceutical industrial pollution control technology and policy, 2009); gross industrial production rapidly increased by $175.97 \%$ from 425.45 billion RMB in 2005 to

\footnotetext{
* Corresponding author. Tel./fax: +86 1062849109.

E-mail address: yswei@rcees.ac.cn (Y. Wei).
}

1174.13 billion RMB in 2010 ( 1 US\$ $=6.12$ RMB at the current exchange). Though the wastewater discharged from the pharmaceutical industry in China only increased by $31.33 \%$, from 400.5 million ton in 2005 to 526.0 million ton in 2010 (National Bureau of Statistic China, 2010) because of the promotion of cleaner production and pollution control, wastewater treatment in the pharmaceutical industry is listed as one of the 12 major industries because of the environmental planning and more stringent discharge standards issued in China (Table S1).

Currently, most pharmaceutical wastewaters are treated with conventional biological treatment processes; however, the effluent treated in such a way still contains significant amounts of color compounds and recalcitrant organic compounds (Xing and Sun, 2009) and does not meet the discharge standards prescribed by 
the Chinese government. Amin et al. (Amin et al., 2006) reported that antibiotics ranging from ng $\mathrm{L}^{-1}$ up to a few $\mu \mathrm{g} \mathrm{L}^{-1}$ have been detected in the wastewaters and surface waters. Worse still, certain point sources such as pharmaceutical production facilities may have much higher antimicrobial concentrations in their effluent, i.e., a few $\mathrm{mg} \mathrm{L}^{-1}$. Recently, it was reported that the incidence of antibiotic resistant bacteria (ARB) has increased, and it is believed that the increase is due to the use of antibiotics (Alexy et al., 2004). Therefore, antibiotic production wastewater treatment has become a source of concern because of the antibiotic resistance genes (ARGs) of ARB, which may pose a great potential health risk to humans (Elmolla and Chaudhuri, 2011). Therefore, new technologies and advanced treatments for pharmaceutical wastewater treatment must be developed to meet the strict discharge standards and promote wastewater reuse.

Membrane technology has gained popularity in recent years as an efficient technology for pharmaceutical wastewater treatment. Membrane bioreactors (MBR) offer several prominent advantages over the conventional activated sludge (CAS) process, including higher biomass concentration, smaller footprint, less sludge production, and higher effluent quality (Wang et al., 2009). However, Kim et al. (2007) reported that an MBR also showed limited target compound removal. Moreover, inorganic compounds such as salts in antibiotic production wastewater cannot be removed effectively via biological treatment. Therefore, post treatment steps are required to obtain excellent-quality water. In recent years, nanofiltration membranes (NFs), which have high retention for multivalent ions and organic matter at low operating pressure, have received more attention for wastewater treatment and reclamation. NF membranes can effectively remove COD and colored components from biological wastewater treatment effluent (Choi et al., 2008). Snyder et al. (2007) reported that reverse osmosis (RO) and nanofiltration (NF) membranes provide effective barriers for the retention of contaminants and can remove target pollutants with high efficiency. Shah et al. (2012) evaluated the mechanisms of antibiotic removal by NF membranes to improve understanding of the transport mechanisms.

In view of the advantages of MBR and $\mathrm{RO} / \mathrm{NF}$, dual membrane systems of MBR and RO or NF have recently received attention as promising alternative treatments for trace organic pollutants removal or water recycling (Alturki et al., 2010; Joss et al., 2011). However, most of the systems have been used for treating municipal wastewater because of the excellent water quality of the MBR effluent, and there are few reports on the direct use of the dual membrane system for treating industrial wastewater to meet stringent discharge standards or reuse. The MBR effluent of industrial wastewater often contains high concentrations of pollutants, especially organics; therefore, another treatment process (e.g., ultrafiltration (UF)) is typically used between the MBR usage and NF/RO process as a pretreatment or safeguard process for NF/RO (Zhang et al., 2009). Meanwhile, the treatment of the NF/RO concentrate in these double membrane systems is still a challenge, and to our knowledge, there are no reports on the combined MBR-NF/RO process for treating industrial wastewaters containing recycled NF/RO concentrate by using MBR. In addition, antibiotic production wastewater is mainly polluted by organic matter, and knowing the fate of that matter in the treatment plant is important. However, this research is scarce in the literature.

In this study, a pilot-scale combined MBR-NF process for treatment of antibiotic production wastewater was tested with the recycling of the NF concentrate to the MBR for the first time in China. This was done over a three-month period on-site at a pharmaceutical company. To obtain a high water yield, part of the NF concentrate was recycled back into the aeration tank of the MBR. The performance of the pilot system for treatment of antibiotic production wastewater was investigated by comparing it with an antibiotic production wastewater treatment station, and the fate of organic pollutants in the process was identified by fluorescence excitation-emission matrix (EEM) spectrometry, Fourier transform infrared spectroscopy (FT-IR), and high-pressure size-exclusion chromatography (HPSEC). Moreover, the microbial community of the pilot system was characterized using multiple techniques, including real-time PCR, denaturing gradient gel electrophoresis (DGGE), and clone library construction.

\section{Materials and methods}

\subsection{Wastewater characteristics}

The feed water used for the pilot MBR-NF system was the effluent of the anaerobic process from a wastewater treatment station of a pharmaceutical company producing spiramycin in Wuxi, China. The characteristics of the raw wastewater and effluent of the anaerobic process are shown in Table S2. The feed water had high concentrations of organic compounds and $\mathrm{NH}_{4}^{+} \mathrm{N}$. The main antibiotics in the wastewater were spiramycin (SPM) and new spiramycin (NSPM), in $20.38-22.01 \mathrm{mg} \mathrm{L}^{-1}$ and $10.21-10.51 \mathrm{mg} \mathrm{L}^{-1}$, respectively, in the raw wastewater, and in $1.99-2.79 \mathrm{mg} \mathrm{L}^{-1}$ and $0.98-1.35 \mathrm{mg} \mathrm{L}^{-1}$, respectively, in the effluent from the anaerobic process.

\subsection{Experimental setup}

The pilot MBR-NF system was built at a pharmaceutical company in Wuxi, China. To fabricate the MBR-NF system, an MBR was first built followed by the fabrication of an NF setup over the MBR.

The MBR was continuously operated for more than three months from June 1, 2012, to September 6, 2012, and pumped directly from the anaerobic effluent mentioned above. Flat-sheet membrane plates $(0.1 \mu \mathrm{m}$ pore size for plates with area $34 \times 0.25 \mathrm{~m}^{2}$, polyvinylidene fluoride, Sinap, China) were submerged in an aerobic tank with an effective volume of $1.5 \mathrm{~m}^{3}$. Intermittent membrane suction was applied with $6 \mathrm{~m}$ of suction followed by a $2 \mathrm{~m}$ idle. During the MBR operation, $\mathrm{Na}_{2} \mathrm{CO}_{3}$ was added to the MBR tank to maintain the $\mathrm{pH}$ at $7.09 \pm 0.4$. The operational conditions of the MBR are listed in Table S2.

The NF unit consisted of two single centrifugal pumps equipped with two frequency modulators for pressure generation and internal recycling. Two polyamide thin-film composite membrane modules (Filmtec ${ }^{\mathrm{TM}}$ NF90-2540, Dow, USA) operated in parallel with surface area $5.2 \mathrm{~m}^{2}$. The NF unit operated at a transmembrane pressure (TMP) of 5.0 bar on days $62-76$ and 7.5 bar on days 7796 at a cross-flow rate of $2.0 \mathrm{~m}^{3} \mathrm{~h}^{-1}$. Operational conditions of the NF are listed in Table S3. The NF membranes were chemically cleaned every nine or ten days, including an acid cleaning process at $\mathrm{pH}$ 2.0-2.5 with diluted concentrated hydrochloric acid $(\mathrm{HCl}$, $37 \%$ ) and a basic cleaning process at $\mathrm{pH} 10.0-10.5$ with $0.3 \mathrm{wt} \%$ sodium dodecyl sulfate ( $\mathrm{NaDS}, \mathrm{C}_{12} \mathrm{H}_{25} \mathrm{SO}_{4} \mathrm{Na}$ ).

During the test period, the operation of the pilot MBR-NF system was divided into two stages. In the 1st stage, only the MBR was operated during days $0-60$. The HRT of the MBR was set within 30-36 h based on our previous HRT optimization results (Cheng, 2012). On day 62, the NF unit was operated by connecting it with the MBR, and the NF concentrate was first stored in a buffer tank and then returned to the aeration tank of the MBR at the set water yield of $90 \%$. Fig. S1 shows the scheme and calculation method for the water yield in the pilot MBR-NF. Parts of the produced NF permeate were stored in a tank for NF chemical cleaning. The flow rate of the pilot MBR-NF system was $0.52 \pm 0.08 \mathrm{~m}^{3} \mathrm{~d}$. 


\subsection{Antibiotic production wastewater treatment station}

The antibiotic production wastewater treatment station in the pharmaceutical company consists of an anaerobic reactor and oxidation ditch (OD). Operational conditions of the OD are also listed in Table S2.

\subsection{Analytical methods}

Wastewater parameters such as $\mathrm{COD}_{\mathrm{Cr}}, \mathrm{NH}_{4}^{+}-\mathrm{N}$, and TP were determined according to standard methods (APHA, 1998). Total organic carbon (TOC) was determined using a TOC-VCPH analyzer (Shimadzu, Japan). Conductivity was measured with a conductivity meter (HI4321, Hanna, Italy), and turbidity with a turbidity meter (Turb 550, WTW, Germany).

\subsubsection{Antibiotics analysis}

The concentrations of SPM and NSPM were determined using ultra performance liquid chromatography with tandem mass spectrometry (Waters Corp., USA). Each sample of $0.5 \mathrm{~mL}$ was extracted with $1.0 \mathrm{~mL}$ butyl acetate by vortexing for $1 \mathrm{~m}$, followed by centrifugation at $10000 \mathrm{rpm}$ for $3 \mathrm{~m}$. The same extraction procedure was repeated twice, and all the supernatant was then combined and dried under nitrogen. Finally, the sample was dissolved by an acetonitrile/water solution $(1: 1, v / v)$ and diluted to an appropriate concentration for analysis. The detection $\operatorname{limits}(S / N=3)$ for SPM and NSPM were $0.03 \mu \mathrm{g} \mathrm{L}^{-1}$ and $0.06 \mu \mathrm{g} \mathrm{L}^{-1}$, respectively. All samples were analyzed in triplicate.

\subsubsection{Toxicity assay}

To assess the toxicity removal efficiency for both the pilot MBRNF system and the antibiotic production wastewater treatment station, a standardized bioluminescence assay with Photobacterium phosphoreum was applied to the water samples. The toxicity assay method is described in the SI.

\subsubsection{Three-dimensional fluorescence excitation-emission matrix spectrometry (3D-EEMs)}

A fluorescence spectrophotometer (F-7000, Hitachi, Japan) was used to investigate the major components and complexity of the organic matter present in the feed and treated water. Before determining the 3D-EEMs, the water samples were diluted and analyzed according to methods described elsewhere (Xiao et al., 2012).

\subsubsection{High-pressure size exclusion chromatography (HPSEC)}

Gel permeation chromatography (GPC)-UV detection was performed with an HPLC system (Breeze 1525, Waters Co, USA). Full details of the GPC method have been described elsewhere (Ji et al., 2008).

\subsubsection{Fourier-transform infrared spectroscopy (FT-IR)}

Infrared spectra of $2-5 \mathrm{mg}$ of each sample in $\mathrm{KBr}$ pellets were collected on a Fourier transform infrared spectrometer (Nicolet 8700, Thermo Electron Corporation, USA) with a resolution of $4 \mathrm{~cm}^{-1}$ in the range $400-4000 \mathrm{~cm}^{-1}$ to obtain information about the functional groups of the organics in wastewater. Before the FT-IR analysis, the water samples were completely freeze-dried to eliminate water.

\subsubsection{Microbial community analysis}

The bacterial community structures of each biological reactor were characterized using multiple techniques, including polymerase chain reaction-denaturing gradient gel electrophoresis (PCR-DGGE), cluster analysis, clone library construction, and phylogenetic analysis. The detailed analytical methods are described in the SI.

\subsubsection{Statistical analysis}

Statistical analysis was carried out using the software SPSS 11.0 produced by SPSS Incorporation (America) to characterize the differences in treatment effects for the different processes and stages. Correlations are considered statistically significant at a 95\% confidence interval $(P<0.05)$.

\section{Results and discussion}

\subsection{Performance of MBR-NF for treating antibiotic production wastewater}

\subsubsection{Water yield}

As stated above, the HRT of the MBR was reduced from 72 to $60 \mathrm{~h}, 48 \mathrm{~h}, 36 \mathrm{~h}$, and $30 \mathrm{~h}$ by gradually increasing the membrane flux in the 1st stage. Fig. 1a shows the changes in the flux and TMP of the MBR over the entire experimental period. TMP was stable in the pressure ranging between -4.5 and $-7.5 \mathrm{kPa}$ without any chemical cleaning, which showed that the MBR was operated within the required condition. In the 2 nd stage, the NF permeability sharply declined in the first $15 \mathrm{~d}$ (Fig. 1b). To maintain a stable flux in the NF, the TMP was increased from 5.0 to 7.5 bar (Table S3), and the permeability was stable in the following days. The permeability of the NF decreased in the initial period, and this was primarily attributed to an increase in the salt concentration, which will be discussed in the following section. The water yield of the pilot MBR-NF was over $92 \pm 5.6 \%$ for the stable period, similar to Joss's (Joss et al., 2011) study of MBR-NF for treating municipal wastewater.

\subsubsection{Pollutant removal}

Fig. 2 shows changes in the pollutant concentrations in the pilot MBR-NF. In addition, the pollutant concentrations of the OD effluent are also compared (Fig. 2). During the 1st stage (day 0-60), the average COD and TOC concentrations in the MBR effluent were $254 \pm 48$ and $79 \pm 12 \mathrm{mg} \mathrm{L}^{-1}$, slightly lower than the OD effluent at $298 \pm 51$ and $88 \pm 6 \mathrm{mg} \mathrm{L}^{-1}$, respectively. The $\mathrm{NH}_{4}^{+}-\mathrm{N}$ and TP concentrations in the MBR effluent at $9.4 \pm 2.6$ and $3.0 \pm 2.1 \mathrm{mg} \mathrm{L}^{-1}$ were much lower than in the OD effluent, $20.8 \pm 11.2$ and $9.1 \pm 9.5 \mathrm{mg} \mathrm{L}^{-1}$, respectively. The turbidity of the MBR effluent attributed to membrane filtration was much lower than that of the OD effluent. Obviously, the HRT of the MBR could be 30$36 \mathrm{~h}, \sim 50 \%$ of the HRT of the OD (72 h), which would save approximately half of the land area required if a pharmaceutical company used the MBR instead of OD. Statistical analysis results indicated that there was a significant difference in the water quality between the MBR effluent and the OD effluent $(P=0.008$ for COD, $P=0.026$ for TOC, $P=0.001$ for $\mathrm{NH}_{4}^{+}-\mathrm{N}, P=0.006$ for TP, $P=0$ for turbidity). This was consistent with other literature (Malamis and Andreadakis, 2009).

In the 2nd stage, it was clear that the MBR-NF system has an excellent pollutant removal performance (Fig. 2 and Table S4). The NF permeate was characterized by stable and low concentrations of TOC, $\mathrm{NH}_{4}^{+}-\mathrm{N}$, and TP at 5.52, 0.68, and $0.34 \mathrm{mg} \mathrm{L}^{-1}$, respectively. The turbidity of the NF permeate was $\sim 0.15$ NTU. The permeate of MBR-NF met with The reuse of urban recycling water - Water quality standard for industrial uses guideline (GB219032008, China). Generally, recycling the NF concentrate could resolve part of the NF concentrate treatment, but it may also affect the system performance and pollutant removal. To identify the feasibility of this pilot system, the effects of MBR before and after recycling the NF concentrate were compared along with the performance of the antibiotic production wastewater treatment station. The pollutant concentrations in the MBR effluent increased upon recycling of the NF concentrate (Fig. 2). There is a significant difference 

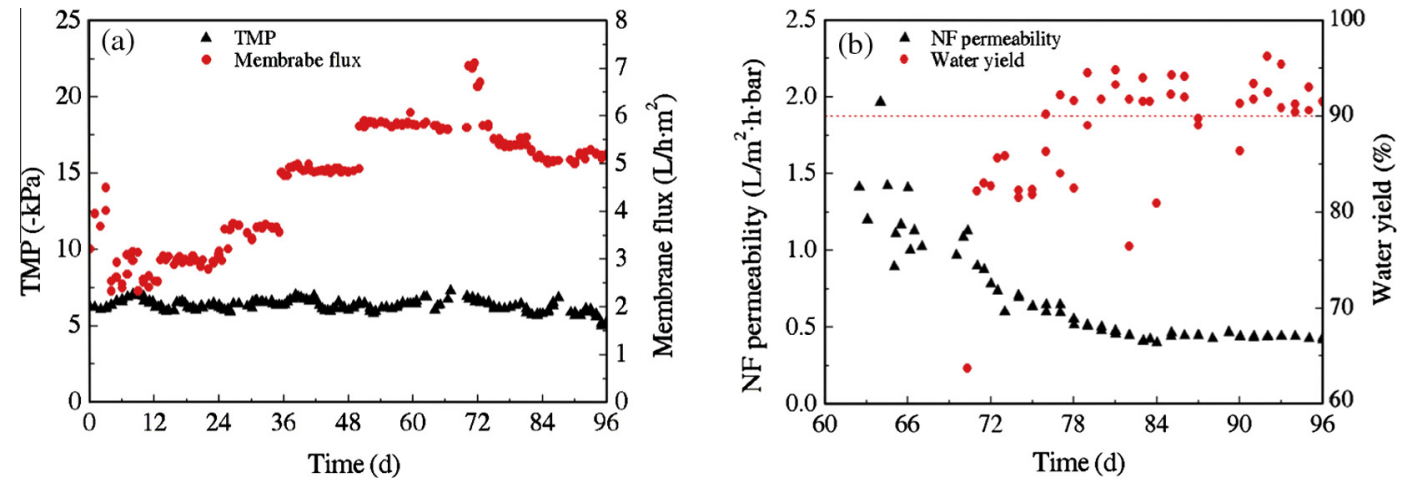

Fig. 1. Performance of the MBR-NF in test period (a) MBR, (b) NF.
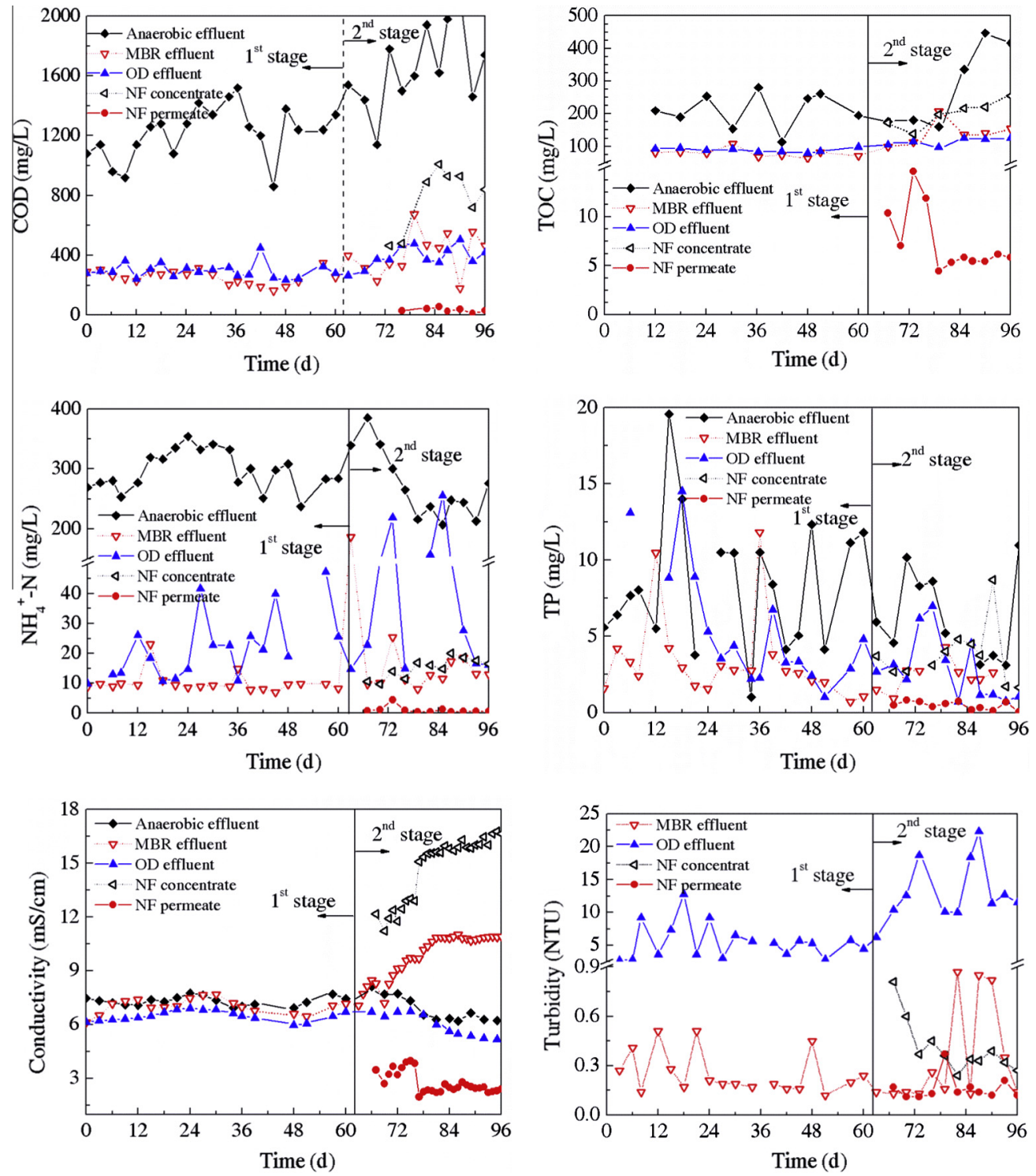

Fig. 2. Changes of $\mathrm{COD}, \mathrm{TOC}, \mathrm{NH}_{4}^{+}-\mathrm{N}$, TP and Conductivity in the MBR-NF and antibiotic production wastewater treatment station.

between the MBR effluent for the 1st and 2nd stages for COD, TOC, and $\mathrm{NH}_{4}^{+}-\mathrm{N}\left(P=0.013\right.$ for COD, $P=0.004$ for TOC, $P=0.007$ for $\mathrm{NH}_{4}^{+}$ $\mathrm{N}, P=0$ for turbidity), indicating NF concentrate recycling has some impact on the MBR performance. However, there is no significant difference between the MBR effluent and the OD effluent in the 2nd stage except for turbidity $(P=0.098$ for COD, $P=0.074$ for
TOC, $P=0.108$ for $\mathrm{NH}_{4}^{+}-\mathrm{N}, P=0.640$ for TP, $P=0.001$ for turbidity), which indicated that they were at the same level of pollutant removal.

Because of the NF membrane retention of inorganic salts, there were significant changes in the conductivity of the pilot system. The conductivity increased sharply in the 2nd stage because of 
concentrate recycling (Fig. 2). However, it eventually stabilized at $\sim 10.8 \pm 0.4 \mathrm{mS} \mathrm{cm}^{-1}$, showing that the pilot system reached equilibrium. This explains why the permeability decreased sharply in the initial stage. The NF permeate stabilized at $\sim 2.5 \pm 0.2 \mathrm{mS} \mathrm{cm}^{-1}$.

The pollutant removal results for the process showed that the pilot MBR-NF resulted in excellent water quality. Recycling the NF concentrate to the MBR may affect the MBR effluent, but there were no effects on the NF permeate. Moreover, the MBR can match the level of conventional biological plants where the water yield is much higher. The pilot MBR-NF performed steadily in the proposed scheme. In addition, we also found that most of the organic pollutants could be removed by recycling the NF concentrate to the MBR, which is another distinct advantage of this system.

\subsubsection{Antibiotics removal}

SPM and NSPM were the two main antibiotics in this wastewater and their concentrations were investigated at the treatment plant. The influent had high concentrations of SPM and NSPM, $\sim 2.79$ and $1.35 \mathrm{mg} \mathrm{L}^{-1}$, in the 2nd stage (Fig. 3). After treatment by biological methods, the removal rate of the two antibiotics became 51-55\%, demonstrating that the biological methods could not effectively remove the antibiotics, and hence, the antibiotics must be subjected to some pretreatment. This also showed that the MBR and OD had similar removal abilities for antibiotics. After NF treatment, the removal rates of SPM and NSPM were over 95\%. This result was consisted with Kim's research (Kim et al., 2007). The antibiotics can be effectively removed through size and charge exclusion. However, there were still trace amounts of antibiotics in the NF permeate after NF treatment. Sahar et al. (2011) also showed that the RO membrane cannot serve as an absolute barrier to organic micropollutants such as macrolides.

\subsubsection{Toxicity removal}

It is required that the aquatic safety level of a water body or wastewater discharged into a water body is evaluated (Liu et al., 2007). However, it has been reported that physicochemical analysis such as COD and TOC alone cannot sufficiently and effectively evaluate the safety of environmental water samples (Fernandez et al., 2005). Biological toxicity tests are a useful tool for investigating the effects of all the bioavailable contaminants and their interactions, and they are widely used to evaluate the safety of environmental samples. Wei et al. (2012) developed a simple assessment method based on the Photobacterium phosphoreum test for toxicity tests and found that it could serve as a valuable tool for evaluating wastewater reclamation processes. In this study, the same method for acute toxicity tests was used to investigate the toxicity variations in the MBR-NF and antibiotic production wastewater treatment station in the 2 nd stage. The results showed that the toxicity indices of Ir decreased to 7\% and 3\% for the MBR effluent and OD effluent compared to that of the influent ( $\mathrm{Ir}=24 \%$, and the value of Ir in the MBR effluent was slightly higher than that in the OD effluent because of NF concentrate recycling. This result was consistent with the other physicochemical parameters mentioned above. After treatment by NF, the value of Ir in the NF permeate became $0 \%$, which showed that the NF membrane played an important role in reducing the toxicity formation potential. The results of the toxicity tests showed that the pilot MBR-NF system is an effective barrier for antibiotic production wastewater reuse.

\subsection{Fate of organics}

\subsubsection{D-EEMs of organics}

The 3D-EEMs spectra are a collection of a series of emission spectra over a range of excitation wavelengths that can be used to identify the fluorescent compounds present in complex mixtures (Wang et al., 2009).

In this study, 3D-EEMs were measured in each stage along the treatment process to analyze the changes in organic matter (Fig. 4). In the 2nd stage, strong tyrosine-like fluorescence and soluble microbial by-product-like fluorescence with maximum peaks at the Ex/Em of 225/335 nm (Peak A) and 275/340 nm (Peak B) (Chen et al., 2003) were found in the influent. After treatment by the MBR unit, the intensities of Peaks A and B significantly decreased. Two new peaks, i.e., Peaks $C$ and $D$, appeared at the Ex/Em of 240/415 and 285/405 nm in the EEM spectra of MBR effluent; these peaks are associated with fulvic acid-like and humic acid-like substances (Chen et al., 2003). This might be because microorganisms can generate nonbiodegradable substances through biodecay effects (Wang et al., 2010). In the NF permeate, the intensity of all the peaks significantly weakened, and these substances were retained in the NF concentrate and treated by the MBR again through recycling.

Fig. 4 and Table S5 show the same changes in the peaks for the 1st stage of the pilot MBR-NF process as well as the OD, but the peak intensities were different. Compared to the MBR effluent in the 1st stage, the maximum peaks of the MBR effluent in the 2nd stage for the tyrosine-like, soluble microbial by-product-like, and fulvic acid-like substances (Peak A, B and C) increased by $2.98 \%$, $24.04 \%$, and $27.17 \%$, respectively. The humic acid-like substances increased sharply, almost doubling, which demonstrated that humic acid-like substances can accumulate in the MBR system. The intensity of the tyrosine-like (Peak A) substance peak in the OD effluent was greater than that in the MBR effluent for both
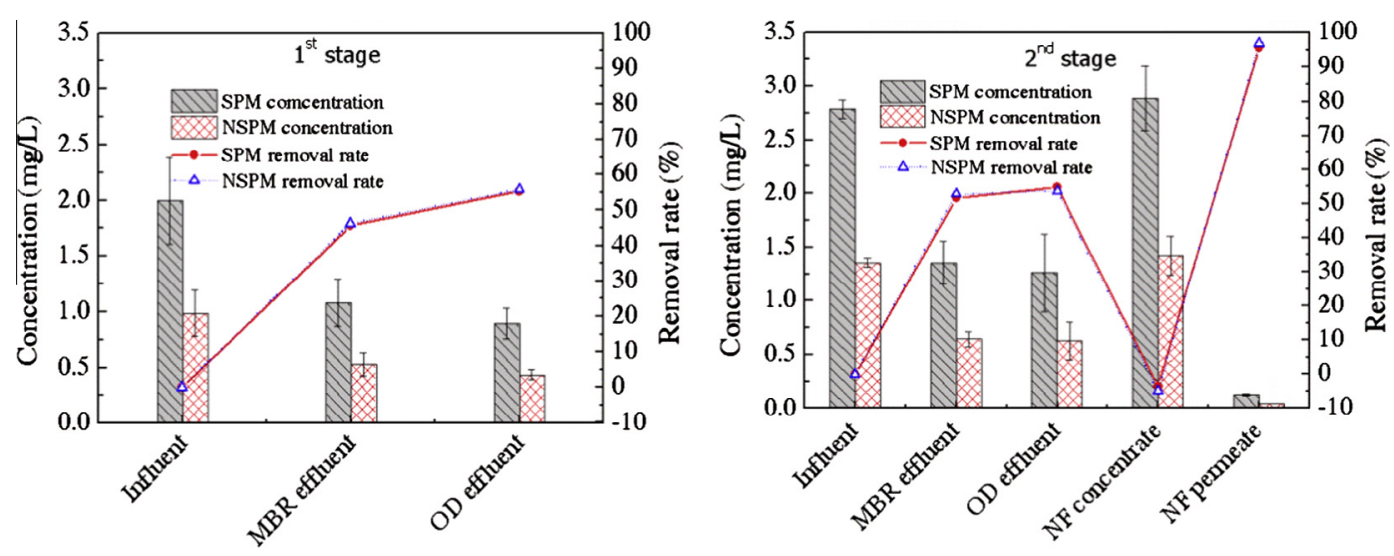

Fig. 3. Changes of antibiotics concentration during the MBR-NF and antibiotic production wastewater treatment station. 

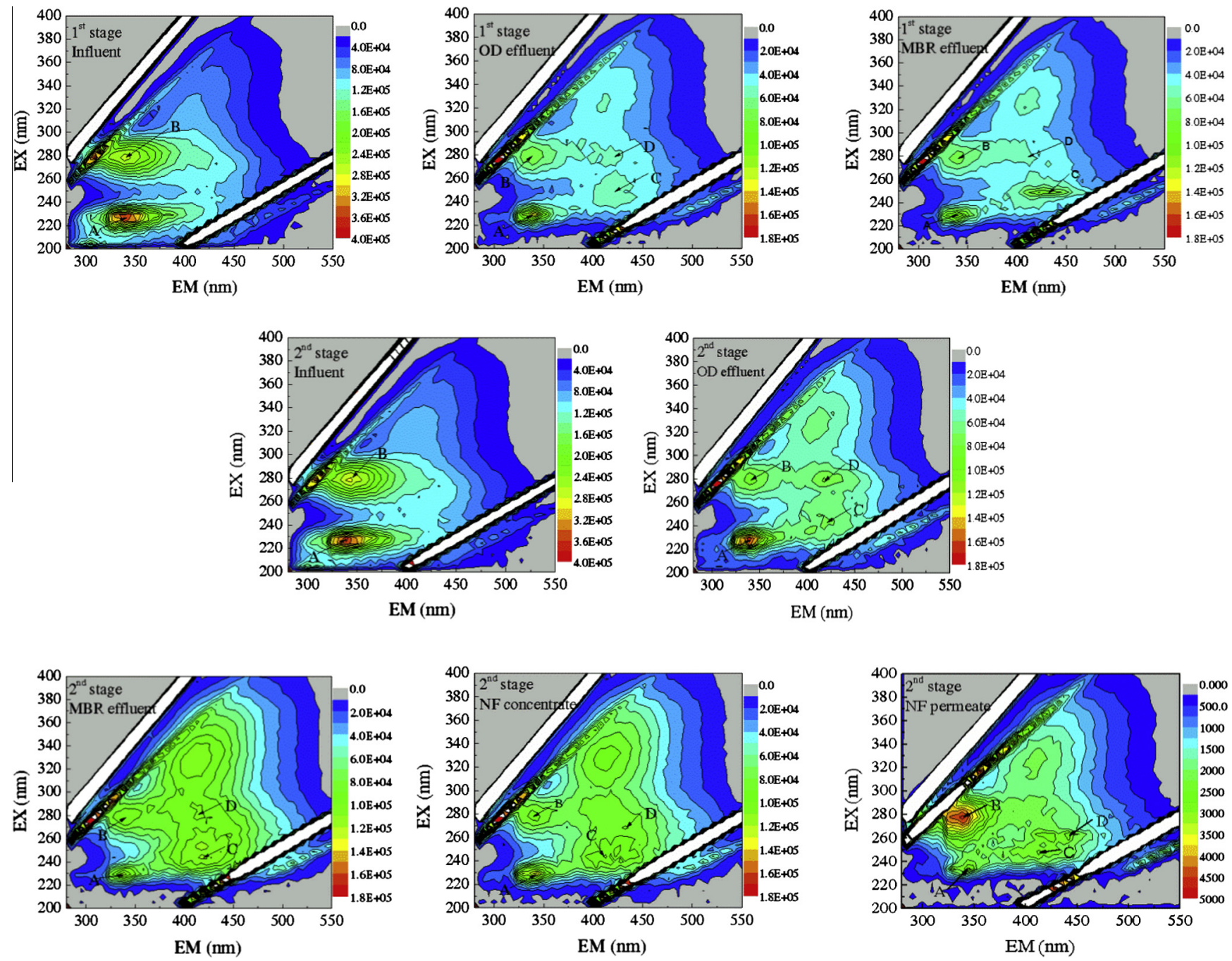

Fig. 4. Fluorescence contour of wastewater in MBR-NF and antibiotic production wastewater treatment station.

the 1st and 2nd stages; this could possibly be attributed to the retention of the MBR membrane. The other three peaks of the OD effluent were higher than those of the MBR effluent in the 2nd stage but lower than those of the MBR effluent in the 1st stage. This phenomenon was possibly related to the NF concentrate recycling.

\subsubsection{FT-IR of organics}

As shown in Fig. 5, there were significant differences in the spectra of the MBR-NF and OD wastewater samples in each stage. Compared to the spectrum of the influent, the peak at $3247 \mathrm{~cm}^{-1}$, which may be due to stretching of the $\mathrm{O}-\mathrm{H}$ bond, and that at $1413 \mathrm{~cm}^{-1}$ (C-N stretch), which is from the secondary and tertiary amines, representing the proteins of the influent disappeared. However, a new peak appeared at $\sim 1380 \mathrm{~cm}^{-1}$, indicating residual nitrate from the biological treatment, and could be seen in the MBR effluent in both the 1st and 2nd stages (Gur-Reznik et al., 2008). The peaks at $\sim 3420 \mathrm{~cm}^{-1}$ for biological wastewater treatment are attributed to the stretching of the $\mathrm{O}-\mathrm{H}$ bond in hydroxyl functional groups (Kumar et al., 2006). Two absorption bands in the MBR effluent in the 2nd stage were observed near 1052 and $1157 \mathrm{~cm}^{-1}$ and assigned to the $\mathrm{C}-\mathrm{O}$ bond of ethers or carboxylic acid, probably a polysaccharide. Absorption in this region indicated the presence of polysaccharide-like/polysaccharides (SMP-like) in the effluent (Cho et al., 1998). Three bands were observed near 1762,1632 , and $1578 \mathrm{~cm}^{-1}$ for the influent and MBR effluent.
These bands correspond to the carbonyl, amide I, and amide II bands of an amide structure, which would be indicative of proteins (Xiao et al., 2012).

Results in the FT-IR contour illustrated that the number of proteins and polysaccharides (SMP-like) in the MBR effluent was more than in both the 1st stage and the influent, and this is the combined effect of aerobic biological degradation and recycling the $\mathrm{NF}$ concentrate. The peak at $680-880 \mathrm{~cm}^{-1}$ is probably due to an aromatic carbon (Howe et al., 2002). The peaks of the NF permeate decreased in both the absorbance intensity and peak quantity, suggesting that most of the polysaccharide-like/polysaccharides, proteins, and SMP-like substances were retained by the NF membrane. The more noticeable peaks in the NF permeate matched proteins with typical bands corresponding to primary and secondary amines at $1375 \mathrm{~cm}^{-1}$ (C-N stretch) and $3417 \mathrm{~cm}^{-1}$ (N-H stretch), polysaccharides with bands at $3416 \mathrm{~cm}^{-1}$ (O-H stretch), and aromatic carbons with peaks at 836 and $825 \mathrm{~cm}^{-1}$, respectively. The peaks of the NF concentrate were almost the same as that of the MBR effluents, demonstrating that the NF membrane mainly works via a physical retention process.

\subsubsection{HPSEC of organics}

Fig. 6 shows the HPSEC changes in the wastewater from the MBR and OD. These results showed both the physical and chemical 

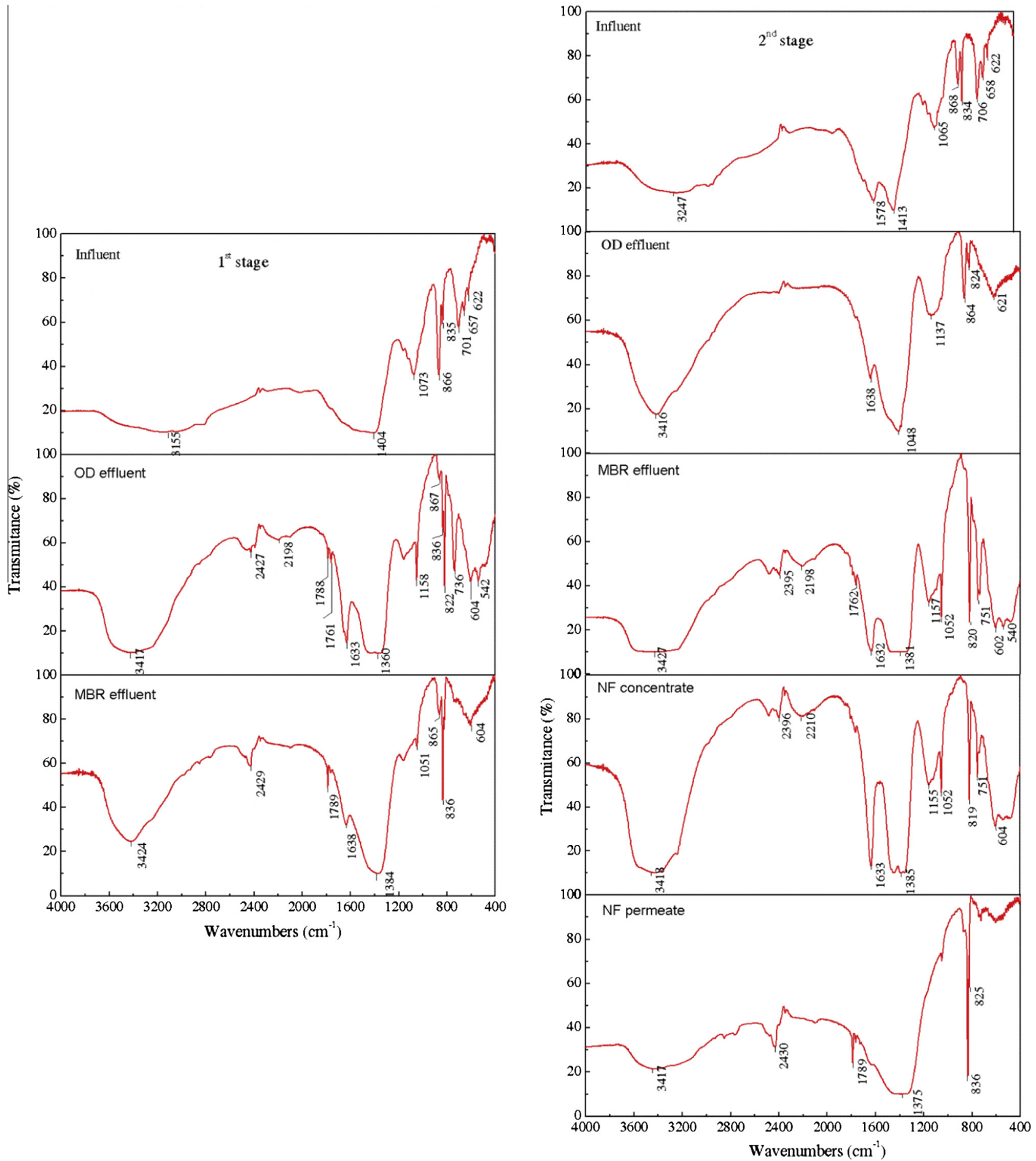

Fig. 5. FT-IR spectra of wastewater in MBR-NF and antibiotic production wastewater treatment station.

properties of the wastewater. The influent showed many peaks that indicated the presence of complex organics. After treatment by aerobic processes such as the MBR and OD, three main peaks were detected in the effluent. The 1st peak corresponded to humic substances, humic and fulvic acids ( $\pm 1000 \mathrm{Da}$ ) (Lee et al., 2004). Proteins and polysaccharides with a characteristic high MW (>10000 Da) were the 2nd and 3rd peaks, which showed significantly higher responses than shown by the humic peak (Lee et al., 2004). However, the three peaks in the MBR effluent for the 1 st stage and that in the OD effluent over the entire stage showed relatively low intensities compared to the MBR effluent in the 2nd stage. The NF concentrate had the highest UV intensity of all the peaks. Malamis and Andreadakis reported that the macromolecule substances showed limited biodegradation owing to their nonbiodegradable character (Malamis and Andreadakis, 2009), which explain the higher accumulation of proteins and polysaccharides in the MBR effluent at the 2 nd stage. These results are consistent with the 3D-EEMs and FT-IR results discussed above. The OD effluent showed another low-intensity peak that represented low-MW organic acids, different from the MBR effluent. 

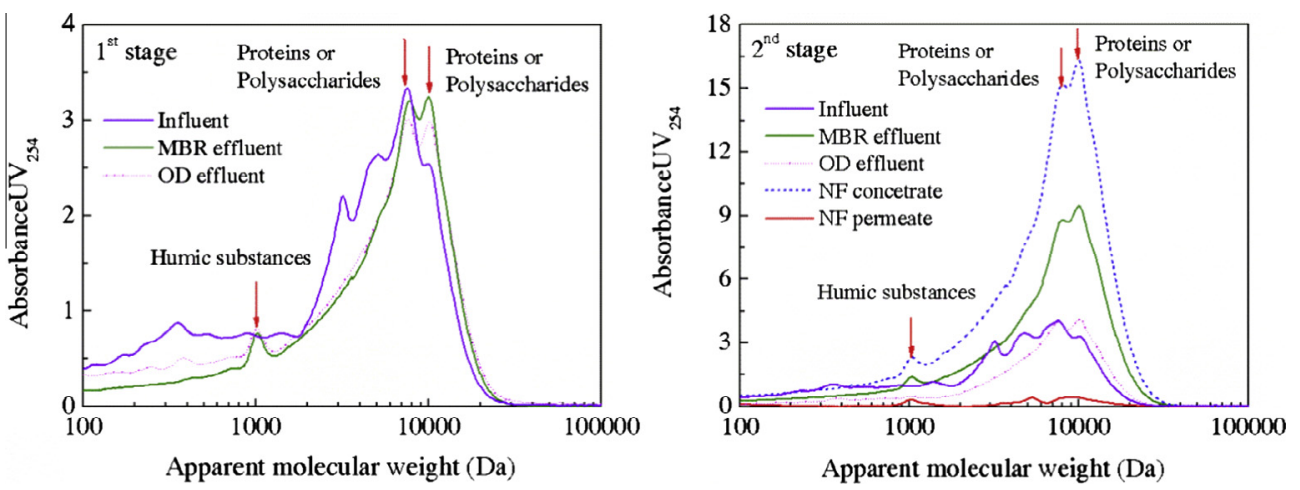

Fig. 6. HPSEC responses of organic matters in wastewater in MBR-NF and antibiotic production wastewater treatment station.

The intensities of the peaks in the NF permeate were nearly zero, illustrating the complete retention of the NF membrane.

All the 3D-EEMs, FT-IR, and HPSEC results showed that the main organics in the effluent of the MBR and OD were proteins, polysaccharides, and humic substances. Because of the NF concentrate recycling, the amount of these substances in the MBR unit increased. However, the pilot MBR-NF system operated stably and showed perfect treatment performances because of the NF process.

\subsection{Microbial community analysis}

The MBR was one of the key units in this pilot MBR-NF system, relating to the stable performance of the entire system. Microorganisms in the activated sludge are the main contributors to biodegradation and removal of pollutants. Thus, investigation of the changes and stability of the microbial community in the MBR was crucial. In this study, a molecular biological technique, PCRDGGE, and clone library construction was used to analyze the difference in the activated sludge samples (Fig. S2). Hesham et al. (2011) demonstrated that each band corresponds to a dominant microbial community member; presence of more bands suggests higher diversity. The microbial communities in each stage of the MBR unit and OD were similar, and all showed rich microbial diversities (Fig. S2). The Shannon diversity listed in Table S6 also showed that both the MBR and OD had abundant species diversity. In the same period ( $\mathrm{C} 1, \mathrm{C} 2$ and $\mathrm{C} 6, \mathrm{C} 7)$, the diversity of the OD was slightly lower than that of the MBR. These results showed that recycling the NF concentrate into the MBR did not change the microbial diversity of the activated sludge.

A phylogenetic tree was constructed from the sequences of the main 25 bands (Fig. S3) in this study, and their closest relative sequences are shown in Table S7. Bacteria belonging to genera Proteobacteria, Firmicutes, and Bacteroidetes were abundant in all the activated sludge processes, which was consistent with Han's (Han et al., 2012) study involving the treatment of municipal wastewater. Fusobacteria, Planctomycetes, and Gammaproteobacteria (including Plesiomonas, Pseudomonas, Vibrio, and Thiothrix) were the most abundant bacteria in this system. This result was the same as that of previous studies, which reported that these bacteria were resistant to high concentrations of antibiotics using pure cultures (Messi et al., 2005; Mindlin et al., 2008). Betaproteobacteria and Bacteroidetes, which exist normally in aerobic biosystems, were also abundant, and it has been reported that they could degrade a variety of pollutants and play important roles in wastewater treatment (Dabert et al., 2001). Deng et al. (2012) reported that Betaproteobacteria and Bacteroidetes could capture and express diverse resistance genes and are central players in the worldwide problem of antibiotic resistance. Moreover, Clostridia and some uncultured bacterium existed in the biological systems, which illustrated that the microbial community was much more complex and abundant than anticipated and can maintain system stability.

\section{Conclusion}

A pilot-scale double membrane of MBR-NF was shown to be effective for the treatment of antibiotic production wastewater by recycling the NF concentrate to the MBR. This combined process of MBR-NF afforded a much high water yield of $92 \pm 5.6 \%$ by recycling the NF concentrate to the MBR tank. The NF permeate retained excellent water quality and could be reused for industrial uses.

The main organics in the effluents of the MBR were proteins, polysaccharides, and humic-like substances, which were almost completely retained by the NF membrane; these organics were accumulated and then biodegraded in the MBR by NF concentrate recycling. The microbial community of the MBR did not significantly change with the recycling of the NF concentrate.

\section{Acknowledgments}

Financial support provided by National High Technology Research and Development Program of China (No. 2009AA063901) and the National Major Science \& Technology Projects for Water Pollution Control and Management (No. 2012ZX07203-002) are gratefully acknowledged.

\section{Appendix A. Supplementary data}

Supplementary data associated with this article can be found, in the online version, at http://dx.doi.org/10.1016/j.chemosphere. 2014.11.034.

\section{References}

Alexy, R., Kumpel, T., Kummere, K., 2004. Assessment of degradation of 18 antibiotics in the Closed Bottle Test. Chemosphere 57 (6), 505-512.

Alturki, A.A., Tadkaew, N., McDonald, J.A., Khan, S.J., Price, W.E., Nghiem, L.D., 2010. Combining MBR and NF/RO membrane filtration for the removal of trace organics in indirect potable water reuse applications. J. Membrane Sci. 365 (12), 206-215.

Amin, M.M., Zilles, J.L., Greiner, J., Charbonneau, S., Raskin, L., Morgenroth, E., 2006. Influence of the antibiotic erythromycin on anaerobic treatment of a pharmaceutical wastewater. Environ. Sci. Technol. 40 (12), 3971-3977.

APHA. Standards Methods for the Examination of Water and Wastewater. 20th ed. American Public Health Association, Washington, DC, 1998.

Chelliapan, S., Wilby, T., Sallis, P.J., 2006. Performance of an up-flow anaerobic stage reactor (UASR) in the treatment of pharmaceutical wastewater containing macrolide antibiotics. Water Res. 40 (3), 507-516.

Chen, W., Westerhoff, P., Leenheer, J.A., Booksh, K., 2003. Fluorescence excitation emission matrix regional integration to quantify spectra for dissolved organic matter. Environ. Sci. Technol. 37 (24), 5701-5710. 
Cheng, Y.T., 2012. Treatment and Reclamation of Antibiotic Wastewater by the Combined Membrane Bioreactor and Nanofiltration. Master Thesis, Chinese Academy of Sciences.

Cho, J.W., Amy, G., Pellegrino, J., Yoon, Y.M., 1998. Characterization of clean and natural organic matter (NOM) fouled NF and UF membranes, and foulants characterization. Desalination 118 (1-3), 101-108.

Choi, J.H., Fukushi, K., Yamamoto, K., 2008. A study on the removal of organic acids from wastewaters using nanofiltration membranes. Sep. Purif. Technol. 59 (1), $17-25$.

Dabert, P., Sialve, B., Delgenes, J.P., Moletta, R., Godon, J.J., 2001. Characterisation of the microbial 16S rDNA diversity of an aerobic phosphorus-removal ecosystem and monitoring of its transition to nitrate respiration. Appl. Microbiol. Biot. 55 (4), 500-509.

Deng, Y.Q., Zhang, Y., Gao, Y.X., Li, D., Liu, R.Y., Liu, M.M., Zhang, H.F., Hu, B., Yu, T., Yang, M., 2012. Microbial community compositional analysis for series reactors treating high level antibiotic wastewater. Environ. Sci. Technol. 46 (2), 795-801.

Elmolla, E.S., Chaudhuri, M., 2011. Combined photo-Fenton-SBR process for antibiotic wastewater treatment. J. Hazard. Mater. 192 (3), 1418-1426.

Fernandez, M.D.M.I., Cagigal, E., Vega, M.M., Urzelai, A., Babin, M., Pro, J., Tarazona, J.V., 2005. Ecological risk assessment of contaminated soils through direct toxicity assessment. Ecotox. Environ. Safe. 62 (2), 174-184.

Gur-Reznik, S., Katz, I., Dosoretz, C.G., 2008. Removal of dissolved organic matter by granular-activated carbon adsorption as a pretreatment to reverse osmosis of membrane bioreactor effluents. Water Res. 42 (6-7), 1595-1605.

Han, Y.P., Liu, J.X., Guo, X.S., Li, L., 2012. Micro-environment characteristics and microbial communities in activated sludge flocs of different particle size. Bioresource Technol. 124, 252-258.

Hesham, A., Qi, R., Yang, M., 2011. Comparison of bacterial community structures in two systems of a sewage treatment plant using PCR-DGGE analysis. J. Environ. Sci. China 23 (12), 2049-2054.

Howe, K.J., Ishida, K.P., Clark, M.M., 2002. Use of ATR/FTIR spectrometry to study fouling of microfiltration membranes by natural waters. Desalination 147 (13SI), 251-255.

Ji, Q.H., Liu, H.J., Hu, C.Z., Qu, J.H., Wang, D.S., Li, J., 2008. Removal of disinfection byproducts precursors by polyaluminum chloride coagulation coupled with chlorination. Sep. Purif. Technol. 62 (2), 464-469.

Joss, A., Baenninger, C., Foa, P., Koepke, S., Krauss, M., McArdell, C.S., Rottermann, K., Wei, Y., Zapata, A., Siegrist, H., 2011. Water reuse: >90\% water yield in MBR/RO through concentrate recycling and $\mathrm{CO}_{2}$ addition as scaling control. Water Res. 45 (18), 6141-6151.

Kim, S.D., Cho, J., Kim, I.S., Vanderford, B.J., Snyder, S.A., 2007. Occurrence and removal of pharmaceuticals and endocrine disruptors in South Korean surface, drinking, and waste waters. Water Res. 41 (5), 1013-1021.

Kumar, M., Adham, S.S., Pearce, W.R., 2006. Investigation of seawater reverse osmosis fouling and its relationship to pretreatment type. Environ. Sci. Technol. 40 (6), 2037-2044.
Lee, N.H., Amy, G., Croue, J.P., Buisson, H., 2004. Identification and understanding of fouling in low-pressure membrane (MF/UF) filtration by natural organic matter (NOM). Water Res. 38 (20), 4511-4523.

Liu, R.R.Y.A., Kameya, T., Kobayashi, T., Sugimura, Y., Kubo, T., Sawai, A., Urano, K. 2007. Evaluating the fish safety level of river water and wastewater with a larval medaka assay. Chemosphere 66 (3), 452-459.

Malamis, S., Andreadakis, A., 2009. Fractionation of proteins and carbohydrates of extracellular polymeric substances in a membrane bioreactor system. Bioresource Technol. 100 (13), 3350-3357.

Messi, P., Guerrieri, E., Bondi, M., 2005. Antibiotic resistance and antibacterial activity in heterotrophic bacteria of mineral water origin. Sci. Total Environ. 346 (1-3), 213-219.

Mindlin, s.z., Soina, V.S., Petrova, M.A., Gorlenko, Z.M., 2008. Isolation of antibiotic resistance bacterial strains from Eastern Siberia permafrost sediments. Russ. J Genet. 44 (1), 27-34.

National Bureau of Statistic China, 2010. Industrial Wastewater Discharge and Treatment.

Pharmaceutical Industrial Pollution Control Technology and Policy (Draft), 2009 <http://www.mep.gov.cn/gkml/hbb/bgth/200911/ W020091109526715077565.pdf>.

Sahar, E., David, I., Gelman, Y., Chikurel, H., Aharoni, A., Messalem, R., Brenner, A. 2011. The use of RO to remove emerging micropollutants following CAS/UF or MBR treatment of municipal wastewater. Desalination 273 (1), 142-147.

Shah, A.D., Huang, C.H., Kim, J.H., 2012. Mechanisms of antibiotic removal by nanofiltration membranes: Model development and application. J. Membrane Sci. 389, 234-244.

Snyder, S.A., Adham, S., Redding, A.M., Cannon, F.S., DeCarolis, J., Oppenheimer, J., Wert, E.C., Yoon, Y., 2007. Role of membranes and activated carbon in the removal of endocrine disruptors and pharmaceuticals. Desalination 202 (1-3), $156-181$.

Wang, Z.W., Tang, S.J., Zhu, Y.F., Wu, Z.C., Zhou, Q., Yang, D.H., 2010. Fluorescent dissolved organic matter variations in a submerged membrane bioreactor under different sludge retention times. J. Membrane Sci. 355 (1-2), 151-157.

Wang, Z.W., Wu, Z.C., Tang, S.J., 2009. Extracellular polymeric substances (EPS) properties and their effects on membrane fouling in a submerged membrane bioreactor. Water Res. 43 (9), 2504-2512.

Wei, D.W.R.A., Tan, Z., Du, Y., 2012. Toxicity-based assessment of the treatment performance of wastewater treatment and reclamation processes. J. Environ. Sci. China 24 (6), 969-978.

Xiao, P., Xiao, F., Wang, D.S., Qin, T., He, S.P., 2012. Investigation of organic foulants behavior on hollow-fiber UF membranes in a drinking water treatment plant. Sep. Purif. Technol. 95, 109-117.

Xing, Z.P., Sun, D.Z., 2009. Treatment of antibiotic fermentation wastewater by combined polyferric sulfate coagulation, Fenton and sedimentation process. J. Hazard Mater. 168 (2-3), 1264-1268.

Zhang, Y., Ma, C., Ye, F., Kong, Y., Li, H., 2009. The treatment of wastewater of paper mill with integrated membrane process. Desalination 236 (1-3), 349-356. 